\title{
Alcohol use among young adolescents in Belgium, the Netherlands, Germany and Austria: The effects of type of education
}

\begin{abstract}
The present study elucidates the association between students' education type and alcohol use, controlling for other socio-economic background characteristics. A subsample of data from the second International Self-Reported Delinquency Study was used $(\mathrm{N}=10,525)$, collected among adolescents in the seventh to ninth grades of secondary school in four Western European countries (Belgium, the Netherlands, Germany and Austria). Data were analysed with multilevel logistic regression techniques. There is an indication that type of education affects prevalence rates of drunkenness and heavy episodic drinking; these effects prove robust for differences in socio-economic backgrounds. In all countries except Belgium, students in education types of lower status show higher prevalence rates for drunkenness and heavy episodic drinking. Lifetime alcohol prevalence rates do not vary much between students from different educational tracks. The results of this study support the literature regarding the role of the educational system in the reproduction of health inequalities and underscore the finding that students from education types of lower status are at greater risk than those from higher status types.
\end{abstract}

Keywords: alcohol use, heavy episodic drinking, binge drinking, educational stratification, tracking, socio-economic differences

Acknowledgements:

We would like to thank the members of AAA-Prevent Research Group: Majone Steketee, Harrie Jonkman, Claire Aussems and Jessica van den Toorn, Verwey-Jonker Institute, Utrecht, the Netherlands; Anna Markina and Kristjan Kask, University of Tartu, Tallinn, Estonia; Uberto Gatti and Alfredo Verde, University of Genoa, Italy; Jiri Burianek and Zuzana Podana, Charles University Prague, Czech Republic; Herbert Scheithauer and Kristin Göbel, Freie Universität Berlin, Germany; Renate Soellner and Astrid Bräker, University of Hildesheim, Germany; Nicole Vettenburg and Hans Berten, Ghent University, Belgium. 


\section{Introduction}

The use of alcohol is a widespread phenomenon in adolescence, and the world's highest alcohol consumption levels among teenagers are found in the developed world, including Western and Eastern Europe (WHO, 2011). Although for most teenagers adolescence is a phase of experimentation in the first place (Boyer, 2006; Irwin, Igra, Eyre, \& Millstein, 1997), heavy episodic drinking and alcohol use at too young an age is not without harm. Many studies acknowledge the acute and longer-range health implications of these behaviours, and the social and economic consequences that accompany with it, both on a personal and on a societal level (Ellickson, Tucker, \& Klein, 2003; Hawkins, Catalano, \& Miller, 1992; Spoth, Greenberg, \& Turrisi, 2009; STAP, 2003). Teenagers who start consuming alcohol early in adolescence are more vulnerable to its negative effects and have a higher chance of developing problematic drinking in later adulthood. In the light of such findings, the European Commission (2006) supports its member states in increasing legal age limits for purchase or consumption of alcoholic beverages, and delaying the onset of alcohol consumption has become a central aim in prevention programmes.

According to the latest ESPAD study (European School Survey Project on Alcohol and Other Drugs) (Hibell et al., 2007), 61\% of 15-16-year-old students in the European countries had drunk alcohol in the last month, $18 \%$ of them reported that they had been drunk in that period, and $43 \%$ reported having had five drinks or more on the same occasion during the last 30 days (i.e. heavy episodic drinking). Prevalence rates of alcohol use, drunkenness and heavy episodic drinking, however, show some variation between European states (Hibell et al., 2007). In some countries, teenagers tend to drink more often but in smaller quantities (e.g. Southern European countries), whereas in other countries (e.g. Nordic countries) alcohol is consumed less often but in larger quantities. The ESPAD study further shows that alcohol use among European youth appears to be stabilizing or even decreasing when it comes to alcohol lifetime and last-month prevalence rates. Problematic drinking is increasing amongst adolescents, however, and the number of girls who are getting involved in problematic drinking is rising (Hibell et al., 2007).

Given these tendencies towards alcohol use, developing effective interventions in public health and gaining insight into the risk factors that constitute teenage alcohol use are important. One of the risk factors that have been documented thoroughly in academic literature relates to the socio-economic position of adolescents in society. Although the literature on differences in adolescents' alcohol use according to the socio-economic background characteristics of family are rather mixed (Andersen, Holstein, \& Due, 2006; Droomers, Schrijvers, Casswell, \& Mackenbach, 2003; Hanson \& Chen, 2007; Humensky, 2010; Richter, Leppin, \& Gabhainn, 2006; Vereecken, Maes, \& De Bacquer, 2004), several studies have shown clear differences in alcohol use according to educational stratification (Hagquist, 2006; Kinable, 2010; Vereecken et al., 2004). Using a cross-national sample of four Western European countries, we investigate whether type of education has an effect on young adolescents' alcohol use independent of other familial socio-economic background characteristics. We hypothesize that when education type is used as a proxy of individually acquired status, clear differences exist between students from different tracks or streams.

\section{Theoretical background}

Several studies have documented the existence of class-based differences in alcohol use among adults (Dias, Oliveira, \& Lopes, 2011; Droomers, Schrijvers, Stronks, van de Mheen, \& Mackenbach, 1999; Huckle, You, \& Casswell, 2010; Van Oers, Bongers, Van De Goor, \& Garretsen, 1999). People with a high socio-economic status drink more often but in smaller amounts, whereas people with a low socioeconomic background drink alcohol less often but in larger amounts and in a more harmful manner. In adolescence, evidence regarding the existence of socio-economic differences in alcohol use is however much less straightforward. Whereas some researchers found a negative association between socio- 
economic status (SES) and alcohol use (Droomers et al., 2003), others report a positive association (Hanson \& Chen, 2007; Humensky, 2010) or an insignificant relationship (Andersen et al., 2006; Richter et al., 2006; Vereecken et al., 2004). In an attempt to explain these inconsistencies, West (1997) referred to the occurrence of a process of equalization in health outcomes during adolescence. Because the peer group, youth culture and the school environment gain a lot of influence in adolescence, familial background influences are strongly weakened, resulting in relative equality in health across socio-economic groups.

It is questionable however whether this 'homogenization effect' really exists or rather should be interpreted as a consequence of the way in which students' SES is conventionally measured, that is, by using information about parents' socio-economic status. As teenagers withdraw from their parents in search of their own identity, their social position is increasingly determined by their own choices and life course plans (Hagquist, 2000, 2006). Consequently, their socio-economic status is just in the process of forming and it may be no longer sufficient to determine young people's social status merely on parental SES grounds (Currie et al., 2008; Emerson, Graham, \& Hatton, 2006; Williams, Currie, Wright, Elton, \& Beattie, 1997). Also, the use of parental SES markers alone to define students' SES is associated with conceptual and methodological problems (see for instance Currie, Elton, Todd, \& Platt, 1997). To capture social differentiation in early adolescence fully, we also need to take into account teenagers' individual socio-economic position (Magklara et al., 2010; Paavola, Vertanen, \& Haukkala, 2004). This can be extrapolated from information about current educational level, since this to a large extent determines future career and social class (Bourdieu \& Passeron, 1977).

Characteristic of some European countries is a school system with a high degree of educational stratification. Educational stratification is defined as grouping students according to their abilities, whether by tracking, streaming, or some other approach (Van Houtte \& Stevens, 2008). One reason for this practice is that students are expected to have different careers and thus need to learn different skills and knowledge. Another motivation is that teaching a homogeneous group of students is considered more efficient as it allows teachers to direct lessons toward the specific ability level of the students in each class. Notwithstanding these good intentions and the fact that different kinds of educational levels are needed in a society, there is growing evidence that tracking also has adverse effects. Studies on the sociology of education (e.g. Hallinan, 1994; Van Houtte \& Stevens, 2008) have shown that belonging to a higher track positively influences academic achievement and that the reverse holds for belonging to a lower track. In a similar vein, several studies have illustrated that students on lower educational tracks use alcohol to a more harmful degree than their counterparts on the upper tracks (Berten et al., 2012; Hagquist, 2006; Kinable, 2010; Vereecken et al., 2004).

Bourdieu and Passeron (1977) see schools as important agents of cultural reproduction. This reproduction of inequalities is accomplished by means of processes of selection and socialization. Selection refers to the process through which middle-class students are tracked into the higher status education types, whereas pupils who lack the 'right cultural capital' - e.g. lower-class students and students from ethnic minority groups - become entangled in what is described as a "waterfall mechanism' and thus are steered towards lower levels of education (Nicaise, 2008; Van Rossem, Berten, \& Van Tuyckom, 2010; Vettenburg, 1988, 1998). Schools, however, also socialize students into particular cultures: higher-status education types socialize students towards the dominant middleclass cultures, whereas lower-status education types socialize them towards lower-class cultures (Bourdieu \& Passeron, 1977; Vettenburg, 1988, 1998).

According to Vettenburg $(1988,1998)$, teenagers from lower social classes are projected in a downward spiral of societal vulnerability during their socialization in school, caused by the discrepancy between their family culture and the middle-class school culture (see also Bourdieu \& Passeron, 1977). This cultural gap affects teachers' attitudes to and expectations of students of lower socio-economic backgrounds and thwarts the development of a positive tie between teachers and lower-class pupils. It also explains why lower-class students often end up on the lower educational tracks (i.e. the waterfall mechanism). Several studies have shown that teachers in lower tracks often think of their students as 'educational failures' and 'unruly', have lower expectations and give fewer positive stimuli (Bowles \& Gintis, 1976; Pelleriaux, 2001; Rosenthal \& Jacobson, 1968; Vettenburg, 
1988, 1998). This fosters an overall school climate in vocational programmes characterized by little to no interest in academe or school, feelings of being held back and of bleak future prospects, strained relations with teachers and school administration, poor study motivation, boredom, a sense of futility, eroded self-esteem, etc. (Pelleriaux, 2001; Schafer \& Olexa, 1971; Van Houtte, 2005, 2006; Vettenburg, 1988, 1998). To handle the strain induced by these experiences, students seek support from similarly stigmatized teenagers with whom they develop a system of anti-values (Vettenburg, 1988, 1998). Moreover, research has shown that the cultures that emerge under these circumstances emphasize masculinity and social status as crucial elements of identity (Askew \& Ross, 1990; Epstein, 2009; Mac an Ghaill, 1994; Willis, 1977). The set of anti-values that develops among these teenagers may then provide them with alternative sources of social status (e.g. risky behaviour, delinquent behaviour, alcohol and drug use, etc.), to compensate for their lack of status in domains related to academic performance, and this whole process may drive them further away from conformity (Vettenburg, 1988, 1998). Consequently, the existing social divisions are perpetuated and social inequalities are reinforced. Following this line of reasoning, we expect that education type, as a proxy for students' current social position, will affect students' alcohol use regardless of their socioeconomic background.

In summary, the present study analyses the association between students' educational level and alcohol use. The study contributes to the literature because it investigates this relationship by (1) holding constant the differences in socio-economic background characteristics of students' families on the one hand, and (2) studying this relationship in four Western European countries on the other hand. The latter allows us to investigate these gradients in a cross-national perspective, thus enhancing the external validity of the findings. These four countries (i.e. the Netherlands, Belgium, Germany and Austria) were selected not only because they have quite similar alcohol use patterns but also because they have a highly tracked educational system from the first year of secondary school onwards. This contrasts with other countries that do not differentiate between tracks or where the choice is postponed until later years. The cross-national research design enables us to look in an explorative way at how the effect of education type on teenage alcohol use varies according to country. We expect that the relationship will be in the same direction in all countries, that is, that students on lower educational tracks will have higher prevalence rates of drinking alcohol than students on the upper tracks. In the light of two of the central aims of alcohol prevention (i.e. targeting problematic drinking and underage drinking) this study focuses on three alcohol use measures: lifetime prevalence of (1) drinking alcohol, (2) drunkenness, and (3) heavy episodic drinking. The last is an indicator of problematic alcohol drinking, and the other two measures can be considered indicators of age of onset (i.e. the age at which teenagers start drinking alcohol for the first time). Given the very young adolescents in this study, and given that adolescence is the phase when behaviours such as alcohol use emerge (Boyer, 2006), we can assume that most of the students who report that they have already drunk alcohol have started doing so in this life stage. Although measuring prevalence of drinking alcohol or alcohol drunkenness (i.e. whether students have drunk alcohol /been drunk yet) is not the same as measuring age of onset, a higher prevalence rate also generally implies earlier onset of drinking (especially given the relative age homogeneity of seventh-, eighth- and ninth-grade students). As the literature indicates that people from lower social strata tend to drink alcohol to worse effect than people from higher strata, we expect the effects of education type to be more pronounced for drunkenness and heavy episodic drinking than for alcohol lifetime prevalence.

\section{Methods}

\section{Data}

For the purpose of this paper, we used a subsample of four Western European countries $(\mathrm{N}=10,525)$ from the second International Self-Reported Delinquency study (2006). These countries are Belgium $(\mathrm{N}=2,268)$, the Netherlands $(\mathrm{N}=2,230)$, Germany $(\mathrm{N}=3,033)$ and Austria $(\mathrm{N}=2,994)$. The ISRD-2 study is a large-scale survey on delinquency, alcohol and drug use conducted in 31, mostly European, 
countries. It is a school-based study that uses as the primary sampling unit seventh-, eighth-, and ninth-grade classrooms in secondary school (12-15-year-old students). As for most countries in ISRD2 , a city-based sampling strategy was used for the four countries included here.

The sampling process involved two stages: (1) selection of cities and towns, and (2) random sampling of schools in the selected cities followed by random selection of classrooms from the seventh, eighth, and ninth grades within these schools. The sampling guidelines recommend city-based sampling with about 2,100 respondents per country, whereby each sample includes at least 700 students from a large city or metropolitan area (about 500,000 inhabitants), a medium-sized city (120,000 inhabitants plus or minus $20 \%$ ), and a cluster of small towns (10,000 to 75,000 inhabitants). The data of virtually all countries in the ISRD-2 study may be viewed as representative of students from the seventh, eighth, and ninth grades in secondary school (Enzmann et al., 2010). Nonetheless, it is important to keep in mind that data from a city-based sample are not nationally representative. More detailed background information on the data has been provided elsewhere (Enzmann et al., 2010; Junger-Tas et al., 2010).

As in most school-based studies, the response rate at the school level was low. This was because schools are commonly swamped with survey requests from researchers, generally resulting in a 'first come, first served' outcome. The percentage of schools approached that finally agreed to participate in the study was $17.5 \%$ in the Netherlands, $46.3 \%$ in Belgium, 50.0\% in Germany, and 78.9\% in Austria. When schools refused to participate, the selection procedure was repeated until the desired sample of students, representative of the different education types, was achieved. Although the response rate at the school level was very low, comparisons with school data of registered students indicates that the percentage of students that completed the questionnaire was very high $(99.8 \%$ in the Netherlands, 93.4\% in Belgium, $95 \%$ in Germany, and $99.5 \%$ in Austria). These numbers indicate that attrition related to truancy, illness or another reason was extremely low. These high numbers were achieved because in most countries students who were absent for the initial survey were surveyed at a later date.

Preliminary analyses of the whole dataset of 25 countries (results not shown) indicated that these four countries have quite similar alcohol use patterns when compared with the other European countries in the dataset. Unlike other public survey data, the percentage of missing values was rather low. The variable responsible for most missing observations was 'neighbourhood disorganization' (4.3\%). All other variables had fewer than $2 \%$ missing observations.

\section{Measures}

\section{Dependent variables}

Alcohol lifetime prevalence was measured by asking students whether they had ever drunk alcohol (0 $=$ no, $1=$ yes $)$, and drunkenness prevalence measures by asking if they had ever got drunk $(0=$ no, $1=$ yes).

Heavy episodic drinking: although there is no internationally agreed definition of heavy episodic drinking (also known as binge drinking) we used the same measure as in the ESPAD study (Hibell et al., 2007). Students were asked how many alcoholic drinks (i.e. glasses, cans or small bottles) they had consumed on the last occasion. Adolescents who had drunk five or more were categorized as 'heavy episodic drinkers' (value of one); all other students had a value of zero In line with the ESPAD study, we use the term 'heavy episodic drinking' to differentiate our definition from that of 'binge drinking' as used by the National Institute on Alcohol Abuse and Alcoholism (NIAAA). According to the NIAAA (2004) a binge is a pattern of alcohol drinking that brings the blood-alcohol concentration to 0.08 gram per cent or above. For a typical adult, this corresponds to consuming five or more drinks (males) or four or more drinks (females) in about two hours. Because no time frame is specified in either the ESPAD or the ISRD-2 questionnaire, and to avoid confusion with the NIAAA definition, we used the term heavy episodic drinking. 


\section{Education type}

The school system in these countries is highly tracked and consists of a hierarchy of education types that can be ranked by difficulty level from vocational (the lowest level) to general secondary education (the highest level), with other education types often placed between these two extremes. Whereas 'general education' provides students with a firm theoretical knowledge foundation for higher education, 'vocational education' provides students with technical training for direct entry to the job market. The school types that correspond to the former ('general or academic education') are Algemeen Secundair Onderwijs (ASO) in Belgium, Voorbereidend Wetenschappelijk Onderwijs (VWO) and Hoger Algemeen Voortgezet Onderwijs (HAVO) in the Netherlands, and Gymnasium in Germany and Austria. School types that correspond with the latter ('vocational education') are Beroeps Secundair Onderwijs (BSO) in Belgium, Voorbereidend Middelbaar Beroepsonderwijs (VMBO) in the Netherlands, and Hauptschule in Germany and Austria. Although the education types that correspond to these two extremes are quite comparable between the four countries, there are also some intermediate education types that are more country-specific. Therefore, we opted for a dichotomous categorization wherein we compared students in general or academic education (A-track) with students in all other tracks or streams together (B-track).

\section{Control variables}

Control variables comprised grade, gender, minority status (majority vs. minority), country, and three socio-economic background characteristics. Majority students were defined as students who (1) were born in their country of residence, (2) had at least one parent born in their country of residence, and (3) spoke (one of) the national language(s) of their country of residence at home. The country variable was a categorical variable ( $0=$ Belgium, $1=$ Austria, $2=$ Germany, $3=$ the Netherlands). Because Belgium is the country with the lowest prevalence rates for all alcohol measures, this country was chosen as the reference category.

As regards measuring family socio-economic status, previous studies have indicated that many young adolescents cannot accurately report their parents' income, occupation or educational level (Currie et al., 1997, 2008). Use of these traditional SES indicators leads to problems such as high levels of nonresponse or selective bias, with greater non-response in low socio-economic groups (Currie et al., 2008). Because of these difficulties, the Family Affluence Scale (FAS) has been developed as an alternative measure of parental socio-economic status. The FAS was originally developed by Currie et al. (1997) in the framework of the HBSC study, and has since been validated cross-nationally (Boudreau \& Poulin, 2009; Boyce, Torsheim, Currie, \& Zambon, 2006; Lin, 2011). This validated instrument consists of four items and measures whether the student has (1) a room of his/her own, (2) a mobile phone, and (3) a computer to use at home, and (4) whether the student's family has a car. Responses were summed, with high scores indicating high family affluence (Min= $0, \operatorname{Max}=4)$.

Whereas parental occupation is difficult to collect from young people, this is less true for parental work status. The non-response on this variable was very low (1.75\%), and so this variable was added as a second indicator of family SES. Parental work status measures whether (1) no parents, (2) one parent, or (3) both parents have/has a paid job (i.e. a steady job or an own business).

Although not a traditional SES measure, neighbourhood disorganization was used as a third indicator of students' socio-economic background. Theories such as social disorganization theory (Shaw \& McKay, 1942) and societal vulnerability theory (Vettenburg, 1988, 1998) posit that people who live in disadvantaged neighbourhoods are almost by definition from poor and socially vulnerable families. We measured neighbourhood disorganization using a scale consisting of thirteen items $(1=$ not at all true, 4 = very true). Examples of items are 'This is a close-knit neighbourhood', 'People in this neighbourhood can be trusted', 'There are a lot of graffiti', 'There are a lot of empty and abandoned buildings', 'There is a lot of crime in my neighbourhood', 'There is a lot of fighting', etc. The items were summed; high scores reflected strong neighbourhood disorganization (Min= 5, Max=20). 


\section{Statistical analyses}

We first examined whether socio-demographic variables, education types, and the various alcohol outcomes differed between the four European countries. To examine the effects of education type, a series of multilevel logistic regression models were estimated, controlling for other student characteristics. Because multi-stage cluster sampling was used to select the respondents (students within schools within countries), observations were not completely independent and thus multilevel models were required. To model differences in alcohol use between the groups, a series of randomintercept models was estimated to take this interdependence into account. Given the structure of the data, a three-level model would be most appropriate in the context but in this study only four countries are investigated and because parameter estimates may be unreliable for multilevel models with few higher level groups (Raudenbush \& Bryk, 2002) we opted for a two-level model (i.e. students within schools). To control for variation in alcohol use at the country level, we added the country variable as an indicator at the school level. Two-way interaction terms of education type with the country variable were added to examine if the effects of education type on alcohol use differed between the four countries.

\section{Results}

\section{DESCRIPTIVE STATISTICS}

Table 1 shows the descriptive statistics for the various predictors and outcome variables for the country subsets and the total sample. $\chi 2$-tests (for the categorical variables) and $t$-tests (for the continuous variables) were used to investigate whether significant variation exists in these variables across countries. About two-thirds of the students had already consumed alcohol, and $28.6 \%$ had already been drunk. About $20 \%$ of the students reported drinking more than five glasses of alcohol on the last occasion. It should be noted that significant variation in these percentages exists between the four countries, with Belgium ranking among the countries with the lowest prevalence rates.

The results further demonstrate that the distribution over the two education types is about equal in Germany and the Netherlands. In Austria, students in the lower educational tracks are overrepresented, whereas in Belgium the reverse is true, with $71.6 \%$ of the students following classes in the A-track. Moreover, when split by grade (results not shown), another picture emerges. Respectively $86.0 \%$ and $82.7 \%$ of the students in the first and second grades of secondary school follow classes in the A-track. In the third grade, this percentage decreases to $47.5 \%$, indicating that a very large number leaves the A-track in the third grade of secondary school $(\chi 2=345.72, d f=2, p<0.001)$. In Austria a similar trend is observed: respectively $54 \%$ and $56 \%$ are on the A-track, and this percentage decreases to $24 \%$ in the third grade $\left(\chi^{2}=315.55, d f=2, p<0.001\right)$. In Germany and the Netherlands, the relative distributions over the grades are much more equal, that is, around $50 \%$ on each track in all grades (Germany: $\chi 2=15.53, d f=2, p<0.001$; the Netherlands: $\chi 2=5.70, d f=2, p=$ n.s.).

\section{[Table 1 about here]}

As regards the remaining student characteristics, $73.4 \%$ of the students are majority group students and $64.4 \%$ come from families where both parents work. About one-third have a family in which one parent is unemployed, and only 5.5\% of the students have a family where both parents are unemployed. Further analyses (results not shown) also indicate that all SES indicators are significantly associated with each other. Students living in disorganized neighbourhoods grow up in families of low affluence $(r=-0.09, p<0.001)$ and students whose parents are both unemployed are more often found in families of low affluence ( $F=415.00, p<0.001)$ and families living in disorganized neighbourhoods $(F=69.07, p<0.001)$. As regards the inflow of students to these educational tracks there is a strong indication of selection effects according to students' socio-economic background (see Table 2). $\chi 2$ - 
tests for categorical variables and $t$-tests for continuous variables indicated whether the differences between the educational types were significant. In all countries except Belgium, family affluence is significantly higher in the A-track than in the B-track. Students on the B-track come disproportionately more from disorganized neighbourhoods than their counterparts on the A-track. We can further see that the proportion of students whose parents are both unemployed is significantly higher for the B-track than the A-track, and students with parents who both have a waged job are overrepresented on the A-track. For migrant students we observed a similar trend: B-track education included the highest percentage of migrant students.

[Table 2 about here]

\section{MULTIVARIATE ANALYSIS}

Table 3 summarizes the parameter estimates for the different alcohol outcomes. In a first model we look at the effects of education type, controlled for the other student characteristics. The results in this model confirm that education type has an effect on all alcohol outcomes, even after controlling for other student characteristics. Compared with A-track students (the reference group), students on the Btrack were significantly more likely to have drunk alcohol, to have been drunk, or to have drunk more than five glasses of alcohol on the last occasion. As regards the $z$-values of the test statistics, education type seems to be a more important predictor of heavy episodic drinking than of alcohol lifetime prevalence.

Model 1 of Table 3 shows further that, in line with earlier analyses of the whole European dataset (results not shown), these four countries show quite similar alcohol use as only German students scored significantly higher on all alcohol use indicators than the reference group (i.e. Belgium). Most other student characteristics also proved to be important predictors. Of course, the prevalence rates of alcohol use, drunkenness and heavy episodic drinking are higher in the upper grades. Heavy episodic drinking is more common among men than among women, and no sex differences were found for the other alcohol outcomes. Minority group students not only drink less heavily but their alcohol and drunkenness prevalence rates are also significantly lower than those of majority group students. Regarding the socio-economic background characteristics, students who live in rather disorganized neighbourhoods have higher alcohol and drunkenness prevalence rates and drink more heavily. In contrast, students who live in affluent families also drink more alcohol, and the same holds for students who live in a family where both parents have a paid job, although here these effects are most pronounced for alcohol lifetime prevalence.

\section{[Table 3 about here]}

In a second model, we looked at how the relationship between education type and alcohol use varies by country. For that purpose, three interaction terms were added to the model, calculated as the product of the dichotomous variable for education type and $k-1$ dummy variables for the categorical variable country. Adding this interaction effect to the model significantly improved its fit for alcohol lifetime prevalence $(\chi 2[3]=12.68, p<0.01)$ and heavy episodic drinking $\left(\chi^{2}[3]=17.53, p<0.001\right)$, but not for alcohol drunkenness prevalence $\left(\chi^{2}[3]=5.86, \mathrm{p}<\mathrm{n}\right.$.s. $)$. The significance tests linked to each of the three interaction coefficients are reported in Model 2 of Table 3. These tests are however less informative, because they only test whether the relationship between education type and alcohol use in each of the countries (Austria, Germany, the Netherlands) is significantly different from the relationship in Belgium (the reference group). For alcohol lifetime prevalence, the significance tests indicate that the relationship between education type and alcohol lifetime prevalence is significantly different between Austria and Belgium, but not between Germany and Belgium nor between the Netherlands and Belgium.

An interpretation in terms of expected differences in alcohol use between both education types, split by country, can easily be calculated from the regression equation. For Belgium, the odds for lifetime alcohol prevalence for students on the B-track are $0.92(\exp (-0.079)=0.92)$ times the odds for their 
counterparts on the A-track, whereas for Dutch students these odds $0.95(\exp (0.027-0.079)=0.95)$. These differences are non-significant, however; i.e. the results indicate that in Belgium and the Netherlands there is no relationship between education type and lifetime alcohol prevalence rate. Austrian and German students on the B-track have odds for lifetime alcohol prevalence rates that are respectively 1.81 and 1.33 those of their counterparts in the A-track. The Wald test confirmed that the effect of education type on lifetime alcohol prevalence is significant in Austria $\left(\chi^{2}[1]=14.30, p<\right.$ $0.001)$ and Germany $(\chi 2[1]=4.10, p<0.05)$, but not in Belgium and the Netherlands. Figure 1 gives a visualization of these expected differences in lifetime alcohol prevalence rates between students on the A- and B-tracks.

\section{[Figure 1 about here]}

Table 3 and Figure 2 present the results for alcohol drunkenness prevalence. As one can see from Figure 2, B-track students in Austria, Germany and the Netherlands have higher prevalence rates of alcohol drunkenness than their counterparts on the A-track. More specifically, B-track students in these three countries have odds for alcohol drunkenness prevalence that are respectively 1.67, 1.72 and 1.51 those of their counterparts on the A-track. The Wald tests confirmed that these differences are significant (Austria: $\chi^{2}[1]=10.00, p<0.01$; Germany: $\chi^{2}[1]=14.30, p<0.001$; the Netherlands: $\chi^{2}$ $[1]=7.30, p<0.01)$. Only Belgium clearly deviates from this pattern with no effect of education type. The overall effect of education type on drunkenness is quite similar in Austria, Germany and the Netherlands. In both Austria and Germany, the relationship between education type and drunkenness prevalence is significantly different from the relationship in Belgium. The relationship is however not significantly different between the Netherlands and Belgium.

The same pattern is repeated for the effects of education type on heavy episodic drinking (Table 3 and Figure 3). The chances of being a heavy episodic drinker are respectively 1.91, 2.29 and 2.08 higher for B-track students in Austria, Germany and the Netherlands than for their counterparts on the Atrack. Here also the differences between the tracks are significant (Austria: $\chi^{2}[1]=14.50, p<0.001$; Germany: $\chi^{2}[1]=29.80, p<0.001$; the Netherlands: $\left.\chi^{2}[1]=21.50, p<0.001\right)$. Again, Belgium stands out as a special case, with no observable differences in heavy episodic drinking between A-track and B-track students.

[Figure $2 \& 3$ about here]

\section{Discussion}

The present study examined whether alcohol use differs between students from different educational tracks, independent of their familial socio-economic background. The study adds to the literature in the sense that it investigates social gradients by focusing on SES markers that largely predict adolescents' future social status (Bourdieu \& Passeron, 1977), instead of relying on the traditional parental SES markers. Our results show that, in three of the four countries, students on lower educational tracks, as compared with students on upper educational tracks, have higher lifetime prevalence rates of drinking alcohol, alcohol drunkenness and heavy episodic drinking. These effects prove robust when controlling for other socio-demographic background characteristics. Thus, by holding constant the differences in students' family SES, the estimated effects of education type represent true influences of the school environment, independent of selection effects (related to students' family SES). Additionally, the differences between educational tracks were most pronounced for alcohol drunkenness and heavy episodic drinking. Given the very young age group, the higher prevalence rates of drinking alcohol and alcohol drunkenness among students on lower educational tracks may be considered as a rough indication that these adolescents not only start drinking alcohol earlier but that they do so with the particular aim of getting drunk. These findings are in line with the literature on social gradients in adulthood, showing that people from lower social strata drink alcohol less often but in larger amounts and in a more harmful manner (Dias et al., 2011; Droomers et al., 1999; Huckle et al., 2010; Van Oers et al., 1999). 
The observation that youths on lower educational tracks have, on average, higher prevalence rates of alcohol drunkenness and heavy episodic drinking than those on higher educational tracks may indicate that the former group is at increased risk, not only in terms of developing problematic alcohol consumption patterns but also regarding other health risks in later adulthood (Hanson \& Chen, 2007). Moreover, students on lower tracks incur a double risk because of their background, as they are recruited disproportionately from minority and low-SES families, and because of their school environment, as schools socialize students into particular youth cultures. Although some of this socialization is an intended part of the school culture, much of it is an unintended consequence of the interactions among students and between students and staff. These findings are in line with theories that emphasize the role of the educational system in the reproduction of inequalities (Bourdieu \& Passeron, 1977; Vettenburg, 1988, 1998). We stressed that the cultures that emerge on lower educational tracks put emphasis on masculinity and social status as core elements of pupils' identity (Askew \& Ross, 1990; Epstein, 2009; Mac an Ghaill, 1994; Willis, 1977). Masculinity in this regard may be demonstrated through risk-taking behaviour such as alcohol and drug use (Kulis, Marsiglia, Chase Lingard, Nieri, \& Villar, 2008; Liu \& Iwanoto, 2007). Challenging conformist values by, for instance, using drugs or alcohol in a risky manner may also provide an alternative source of status in the peer group (Vettenburg, 1988, 1998). Alternatively, it may be that alcohol use functions as a coping strategy to cope with states of vulnerability or to handle the strain that accompanies negative school experiences (Elliott, Huizinga, \& Menard, 1989; Vettenburg, 1988, 1998).

The cross-national character of our study additionally allowed us to explore whether the effects of education type differed between the four European countries. In general, we may conclude that these effects were relatively consistent over the different analyses and countries, with only Belgium deviating from this pattern. For heavy episodic drinking and alcohol drunkenness prevalence we observed relatively small or no variability. The observation that effects of education type were absent in Belgium is however at odds with findings of other research on this country (Berten et al., 2012; Vereecken et al., 2004). These studies found clear differences in alcohol use between students on different tracks, independent of familial SES background characteristics. The first study focused on students in all grades of secondary school (first to sixth grades), however, whereas the second one focused on students in third to sixth grades of secondary school. Therefore both studies also have the higher grades in their data, whereas our study focuses only on students in the first grades of secondary school. The observation that no effects were found for education type in Belgium may be explained by the peculiar organization of its educational system. The full tracking structure (i.e. general, artistic, technical or vocational secondary education) only manifests itself from the third grade onwards. The first two grades of secondary school only distinguish between two official tracks (i.e. A-class and Bclass). The B-class in these grades, however, has a very specific status in Belgium. It is intended only for a small percentage of students who have fallen behind in primary school and are not ready yet to make the transition to secondary school (Nicaise, 2008). The definitive decision to follow a particular track or stream is more or less postponed until the second grade of secondary school, and this explains why in the first two grades almost $85 \%$ of the students follow the A-track, a percentage that is much higher than in the other three countries. Thus, the composition of the A-track population is still very heterogeneous in the first two grades, and the 'waterfall' mechanism has yet to manifest itself. We may expect, however, that once the full tracking structure occurs, the social mix will fall apart and students will be distributed disproportionately over the different education types according to their social background. This in turn may lead to higher levels of alcohol drunkenness and heavy episodic drinking in the lower tracks as a consequence of these students' shared experiences and socialization and the specific cultures that develop in these tracks. These cultures do not necessarily crystallize immediately but may develop over the coming years. Other explanations are however possible and future research is necessary to explain these results.

It is important to keep in mind that this study is not without limitations. A first limitation relates to the cross-sectional design, making it difficult to establish causality. Rather than an expression of socialization, the relationship between education type and alcohol use may also be the result of selection processes. For instance, we lack information on the students' alcohol use prior to entering secondary school. Considering the very young age of the adolescents it is however highly improbable 
that the respondents started drinking before entering secondary school. A second limitation relates to the measurement of SES background. We have already pointed to the fact that measuring the socioeconomic status of students is not without problems, as it is only in a nascent stage and thus is not such a stable trait as it is in adulthood. Although family affluence has been put forward as a valid alternative when young adolescents' SES is surveyed, this measure does not fully capture the different dimensions of socio-economic status. It is for this reason that we opted to add neighbourhood disorganization and parental work status as additional indicators of family SES. Although parental work status was clearly correlated with the education type, the effects of this indicator are more difficult to interpret. We made a raw distinction between employed and unemployed parents, but this distinction neglects the diversity in the 'unemployed' category. For instance, mothers who are housewives or parents who cannot work because of long-term illness or for some other reason were categorized as 'unemployed'. This may have resulted in biased estimates as mothers who look after the household may, for instance, have a high-earning or highly educated partner, or may themselves be highly educated but choose deliberately to stay at home.

Another potential drawback is that those students who have already dropped out from the education system are not represented in the study. Problematic drinking behaviours as well as school drop-out (Wetenschappelijke Raad voor het Regeringsbeleid, 2009) are more prevalent in low SES groups and lower education types. If students in vocational tracks leave school earlier, and these drop-outs drink more alcohol, the estimated effect of education type might have been somewhat underestimated. We should add, however, that in all four countries education is mandatory until the ages of 16 (Austria and Germany) and 18 (Belgium and the Netherlands). Given the compulsory nature of the school system and the fact that our data focus on very young adolescents (i.e. 12-15-year-old students), school dropout can be expected to be rather low.

\section{Conclusion}

The findings in this study have important societal implications. Education is in most countries a social right and ought to provide equal opportunities to all children. There is a general consensus in the literature, however, that countries with a strong hierarchical education system, such as the ones in this study, generate inequalities of all kinds. Our study confirmed that lower-status education types tend to recruit disproportionately from the lower social strata and from minority groups, whereas the more academic education types recruit more from among the middle and higher classes and the majority population. Not only do these schools select students from different social strata but they also socialize students differently with undesirable consequences for students of lower-status education types. A voluminous research tradition has shown that such a hierarchical school structure generates important differences in educational outcomes (e.g. learning opportunities, educational attainment, drop-out rates, future educational and occupational plans, etc). In addition, the few studies that have looked at school effects on non-educational outcomes have shown important differences in behavioural outcomes such as sexual behaviour (Van Rossem et al., 2010). Our study complements this literature by showing that such differences also exist with regard to drinking behaviours. Except for Belgium, students on the more academic-oriented tracks have higher prevalence rates of alcohol drunkenness and heavy episodic drinking than students on vocational tracks, and these differences cannot be explained solely by the students' socio-economic background.

A naïve interpretation of our results supports the idea of abolishing the tracking system in secondary schools. This is of course not a desirable solution. As noted in the theoretical section earlier, these tracks have important social functions. A more realistic aim would be the pursuit of a better appreciation of studies on vocational tracks, and to decrease the segregation between students of different tracks (see also Van Houtte, 2005). Another option is to postpone the definitive choice of a particular track until later in secondary school, a recommendation put forward by the Organization for Economic Co-operation and Development (OECD) many years ago (Jacobs, 2012). Previous studies on PISA data have shown for instance that in countries where tracking starts early in secondary school social differences in academic outcomes are more pronounced than in countries where no tracking 
exists or where it is postponed until later years, as in Scandinavian countries (Jacobs \& Rea, 2011). In terms of implications for health education, schools are important contexts for learning behaviours. Although health education should be part of the curricula in all tracks or streams, attention should be paid specifically to students in vocational education types. More particularly, it may be important to develop a differentiated approach to health education according to type of education, as education and learning styles differ widely among the education types. Whereas programmes in the higher tracks may present health knowledge in a more academic fashion, health classes in the lower tracks need to be oriented more towards the everyday practices of their students, with emphasis also on the information-seeking and processing skills of the students (Van Rossem et al., 2010).

\section{References}

Andersen, A., Holstein, B. E., \& Due, P. (2006). School-related risk factors for drunkenness among adolescents: risk factors differ between socio-economic groups. European Journal of Public Health, 17(1), 27-32.

Askew, S., \& Ross, C. (1990). Boys don't cry: Boys and sexism in education. Buckingham: Open University Press.

Berten, H., Cardoen, D., Brondeel, R. \& Vettenburg, N. (2012). Alcohol and cannabis use among adolescents in Flemish secondary schools in Brussels: The effects of type of education. BMC Public Health, 12 (215).

Boudreau, B., \& Poulin, C. (2009). An examination of the validity of the Family Affluence Scale II (FAS II) in a general adolescent population of Canada. Social Indicators Research, 94(1), 29-42.

Bourdieu, P., \& Passeron, J. C. (1977). Reproduction in education, society and culture. London: Sage.

Bowles, S., \& Gintis, H. (1976). Schooling in capitalist America: Educational reform and the contradictions of economic life. London: Routledge \& Kegan Paul.

Boyce, W., Torsheim, T., Currie, C., \& Zambon, A. (2006). The Family Affluence Scale as a measure of national wealth: Validation of an adolescent self-report measure. Social Indicators Research, 78, 473-487.

Boyer, T. W. (2006). The development of risk-taking: A multi-perspective review. Developmental Review, 26(3), 291-345.

Currie, C., Elton, R., Todd, J., \& Platt, S. (1997). Indicators of socioeconomic status for adolescents: the WHO Health Behaviour in School-aged Children Survey. Health Education Research, 12(3), 385397.

Currie, C., Molcho, M., Boyce, W., Holstein, B., Torsheim, T., \& Richter, M. (2008). Researching health inequalities in adolescents: The development of the Health Behaviour in School-Aged Children (HBSC) Family Affluence Scale. Social Science \& Medicine, 66(6), 1429-1436.

Dias, P., Oliveira, A., \& Lopes, C. (2011). Social and behavioral determinants of alcohol consumption. Annals of Human Biology, 38(3), 337-344.

Droomers, M., Schrijvers, C. T. M., Casswell, S., \& Mackenbach, J. P. (2003). Occupational level of the father and alcohol consumption during adolescence: patterns and predictors. Journal of Epidemiology and Community Health, 57, 704-710.

Droomers, M., Schrijvers, C. T. M., Stronks, K., van de Mheen, D., \& Mackenbach, J. P. (1999). Educational differences in excessive alcohol consumption: The role of psychosocial and material stressors. Preventive Medicine, 29(1), 1-10. 
Ellickson, P. L., Tucker, J. S., \& Klein, D. J. (2003). Ten-year prospective study of public health problems associated with early drinking. Pediatrics, 111(5), 949-955.

Elliott, D. S., Huizinga, D., \& Menard, S. (1989). Multiple problem youth: Delinquency, substance use, and mental health problems. New York, NY: Springer-Verlag.

Emerson, E., Graham, H., \& Hatton, C. (2006). Household income and health status in children and adolescents in Britain. European Journal of Public Health, 16, 354-360.

Enzmann, D., Marshall, I. H., Killias, M., Junger-Tas, J., Steketee, M., \& Gruszczynska, B. (2010). Self-reported youth delinquency in Europe and beyond: First results of the Second International SelfReport Delinquency Study in the context of police and victimization data. European Journal of Criminology, 7(2), 159-183.

Epstein, D. (2009). Failing boys? Issues in gender and achievement. Buckingham: Open University Press.

European Commission. (2006). Communication from the Commission of 24 October 2006: An EU strategy to support Member States in reducing alcohol related harm. Brussels: Commission of the European Communities.

Hagquist, C. (2000). Socioeconomic differences in smoking behaviour among adolescents - The role of academic orientation. Childhood - a Global Journal of Child Research, 7(4), 467-478.

Hagquist, C. (2006). Health inequalities among adolescents - the impact of academic orientation and parents' education. European Journal of Public Health, 17(1), 21-26.

Hallinan, M. T. (1994). Tracking: From theory to practice. Sociology of Education, 67(2), 79-84.

Hanson, M. D., \& Chen, E. (2007). Socioeconomic status and health behaviors in adolescence: A review of the literature. Journal of Behavioral Medicine, 30(3), 263-285.

Hawkins, J. D., Catalano, R. F., \& Miller, J. Y. (1992). Risk and protective factors for alcohol and other drug problems in adolescence and early adulthood - Implications for substance-abuse prevention. Psychological Bulletin, 112(1), 64-105.

Hibell, B., Guttormsson, U., Ahlström, S., Balakireva, O., Bjarnason, T., Kokkevi, A., Kraus, L. (2007). The 2007 ESPAD report: Substance use among students in 35 European countries. Stockholm: ESPAD.

Huckle, T., You, R. Q., \& Casswell, S. (2010). Socio-economic status predicts drinking patterns but not alcohol-related consequences independently. Addiction, 105, 1192-1202.

Humensky, J. L. (2010). Are adolescents with high socioeconomic status more likely to engage in alcohol and illicit drug use in early adulthood? Substance Use Treatment, Prevention and Policy, 5, 10 .

Irwin, C. E., Igra, V., Eyre, S., \& Millstein, S. (1997). Risk-taking behavior in adolescents: The paradigm. In Adolescent Nutritional Disorders: Prevention and Treatment, 817, 1-35).

Jacobs, D. (2012). Nul op het rapport voor gelijke kansen [Zero on the report of equal opportunities]. Groot-Bijgaarden: De Standaard. Retrieved from http://www.standaard.be/artikel/detail.aspx?artikelid=ME3Q0TLP.

Jacobs, D., \& Rea, A. (2011). Verspild talent: De prestatiekloof in het secundair onderwijs tussen allochtone en andere leerlingen volgens het PISA-onderzoek 2009 [Wasted talent: The performance gap in secondary school between minority and other students according to the PISA study 2009]. Brussels: Koning Boudewijnstichting. 
Junger-Tas, J., Marshall, I. H., Enzmann, D., Killias, M., Steketee, M., \& Gruszczynska, B. (2010). Juvenile delinquency in Europe and beyond: Results of the Second International Delinquency SelfReport Study. Berlin: Springer.

Kinable, H. (2010). VAD-leerlingenbevraging in het kader van een drugbeleid op school: Syntheserapport schooljaar 2008-2009 [VAD student questionnaire as part of the drug policy on school: Synthesis report for the school year 2008-2009]. Brussels: Vereniging voor Alcohol- en andere Drugproblemen (VAD).

Kulis, S., Marsiglia, F. F., Chase Lingard, E., Nieri, T., \& Villar, P. (2008). Gender identity and substance use among students in two high schools in Monterrey, Mexico. Drug and Alcohol Dependence, 95(3), 258-268.

Lin, Y. (2011). Assessing the use of the Family Affluence Scale as socioeconomic indicators for researching health inequalities in Taiwan adolescents. Social Indicators Research, 102(3), 463-475.

Liu, W. M., \& Iwanoto, D. K. (2007). Conformity to masculine norms, Asian values, coping strategies, peer group influences and substance use among Asian American men. Psychology of Men \& Masculinity, 8(1), 25-39.

Mac an Ghaill, M. (1994). The making of men: Masculinities, sexualities and schooling. Buckingham: Open University Press.

Magklara, K., Skapinas, P., Niakas, D., Bellos, S., Zissi, A., Stylianidis, S., Mavreas, V. (2010). Socioeconomic inequalities in general and psychological health among adolescents: a cross-sectional study in senior high schools in Greece. International Journal of Equity in Health, 9(1-9).

NIAAA. (2004). NIAAA council approves definition of binge drinking. NIAAA Newsletter 2004. National Institute of Alcohol Abuse and Alcoholism. Retrieved from http://pubs.niaaa.nih.gov/publications/Newsletter/winter2004/Newsletter_Number3.pdf.

Nicaise, I. (2008). Ongelijkheid en sociale uitsluiting in het onderwijs: een onuitroeibaar kwaal? [Inequality and social exclusion in education: an uneradicated evil?]. In I. Nicaise \& E. Desmedt (Eds.), Gelijke kansen op school: het kan! Zestien sporen voor praktijk en beleid [Equal school chances: it is possible! Sixteen trails for practice and policy] (pp. 21-53). Mechelen, Belgium: Plantyn.

Paavola, M., Vertanen, E., \& Haukkala, A. (2004). Smoking from adolescence to adulthood. The effects of parental and own socioeconomic status. European Journal of Public Health, 14, 417-421.

Pelleriaux, K. (2001). Demotie en burgerschap: De culturele constructie van ongelijkheid in de kennismaatschappij [Demotion and citizenship: The cultural construction of inequality in the knowledge society]. Brussels: VUB Press.

Raudenbush, S., \& Bryk, A. (2002). Hierarchical linear models: Applications and data analysis methods. Thousand Oaks, CA: Sage.

Richter, M., Leppin, A., \& Gabhainn, S. N. (2006). The relationship between parental socio-economic status and episodes of drunkenness among adolescents: findings from a cross-national survey. $B M C$ Public Health, 6, 9.

Rosenthal, R., \& Jacobson, L. (1968). Pygmalion in the classroom: Teacher expectation and pupils' intellectual development'. New York, NY: Rinehart and Winston.

Schafer, W., \& Olexa, C. (1971). Tracking and opportunity: the locking-out process and beyond. Scranton, PA: Chandler. 
Shaw, C. R., \& McKay, H. D. (1942). Juvenile delinquency in urban areas. Chicago, IL: University of Chicago Press.

Spoth, R., Greenberg, M., \& Turrisi, R. (2009). Overview of preventive interventions addressing underage drinking state of the evidence and steps toward public health impact. Alcohol Research \& Health, 32(1), 53-66.

STAP. (2003). Alcohol: Gezondheidsrisico's voor kinderen [Alcohol: Health risks for children]. Utrecht: STAP.

Van Houtte, M. (2005). Global self-esteem in technical/vocational versus general secondary school tracks: A matter of gender? Sex Roles, 53(9-10), 753-761.

Van Houtte, M. (2006). School type and academic culture: evidence for the differentiation-polarization theory. Journal of Curriculum Studies, 38(3), 273-292.

Van Houtte, M., \& Stevens, P. A. J. (2008). Sense of futility: the missing link between track position and self-reported school misconduct. Youth \& Society, 40(2), 245-264.

Van Oers, J. A. M., Bongers, I. M. B., Van De Goor, L. A. M., \& Garretsen, H. F. L. (1999). Alcohol consumption, alcohol-related problems, problem drinking, and socioeconomic status. Alcohol \& Alcoholism, 34(1), 78-88.

Van Rossem, R., Berten, H., \& Van Tuyckom, C. (2010). AIDS knowledge and sexual activity among Flemish secondary school students: a multilevel analysis of the effects of type of education. $B M C$ Public Health, 10.

Vereecken, C. A., Maes, L., \& De Bacquer, D. (2004). The influence of parental occupation and the pupils' educational level on lifestyle behaviors among adolescents in Belgium. Journal of Adolescent Health, 34(4), 330-338.

Vettenburg, N. (1988). School ervaringen, delinquentie en maatschappelijke kwetsbaarheid. Een theoretische en empirisch onderzoek in het beroepsonderwijs [School experiences, delinquency and societal vulnerability. A theoretical and empirical study in vocational education]. Leuven: KUL. Faculteit Rechtsgeleerdheid, Afdeling Strafrecht, Strafvordering en Criminologie.

Vettenburg, N. (1998). Juvenile delinquency and the cultural characteristics of the family. International Journal of Adolescent Medicine and Health, 10(3), 193-209.

West, P. (1997). Health inequalities in the early years: Is there equalization in youth? Social Science \& Medicine, 44(6), 833-858.

Wetenschappelijke Raad voor het Regeringsbeleid. (2009). Vertrouwen in de school: Over de uitval van 'overbelaste' jongeren [Confidence in school: About attrition of 'overburdened' young people]. Amsterdam: Amsterdam University Press.

WHO. (2011). Global status report on alcohol and health. Geneva: World Health Organization.

Williams, J., Currie, C., Wright, P., Elton, R., \& Beattie, T. (1997). Socioeconomic status and adolescent injuries. Social Science Medicine, 44, 1881-1891.

Willis, P. (1977). Learning to labour: How working class kids get working class jobs. New York, NY: Columbia University Press. 
Table 1. Description of sample: percentages, means (SD); and significance levels for the test statistics

\begin{tabular}{|c|c|c|c|c|c|c|}
\hline \multirow[t]{2}{*}{ Percentages or means (SD) } & \multicolumn{4}{|c|}{ Country } & \multirow[b]{2}{*}{$\mathbf{p}$ (diff.) } & \multirow[b]{2}{*}{$\begin{array}{c}\text { Total } \\
(\mathrm{N}=10,525)\end{array}$} \\
\hline & $\begin{array}{l}\text { Belgium } \\
(\mathrm{N}=2,268)\end{array}$ & $\begin{array}{l}\text { Netherlands } \\
\qquad(\mathrm{N}=2,230)\end{array}$ & $\begin{array}{l}\text { Germany } \\
(\mathrm{N}=3,033)\end{array}$ & $\begin{array}{c}\text { Austria } \\
(\mathrm{N}=2,994)\end{array}$ & & \\
\hline Alcohol ltp ${ }^{\mathrm{a}}$ & 61.29 & 69.38 & 69.91 & 64.51 & $* * *$ & 66.42 \\
\hline Drunkenness ltp & 23.73 & 24.95 & 31.54 & 31.88 & $* * *$ & 28.57 \\
\hline Heavy episodic drinking & 16.16 & 20.61 & 20.94 & 19.93 & $* * *$ & 19.57 \\
\hline Education type & & & & & $* * *$ & \\
\hline A-Track & 71.61 & 48.30 & 46.22 & 38.64 & & 49.98 \\
\hline B-Track & 28.40 & 51.70 & 53.78 & 61.36 & & 50.02 \\
\hline Grade & & & & & $* * *$ & \\
\hline 7 & 33.38 & 34.13 & 32.41 & 23.71 & & 30.51 \\
\hline 8 & 31.92 & 32.15 & 35.01 & 24.32 & & 30.70 \\
\hline 9 & 34.70 & 33.72 & 32.58 & 51.97 & & 38.79 \\
\hline Gender & & & & & n.s. & \\
\hline Boys & 52.25 & 51.17 & 51.27 & 49.28 & & 50.90 \\
\hline Girls & 47.75 & 48.83 & 48.73 & 50.72 & & 49.11 \\
\hline Minority group & & & & & $* * *$ & \\
\hline Majorities & 74.82 & 73.00 & 75.93 & 70.02 & & 73.39 \\
\hline Minorities & 25.18 & 27.00 & 24.07 & 29.98 & & 26.61 \\
\hline Parental work status & & & & & $* * *$ & \\
\hline No parents working & 8.48 & 6.08 & 4.19 & 4.23 & & 5.53 \\
\hline One parent working & 29.70 & 30.77 & 30.48 & 29.49 & & 30.09 \\
\hline Two parents working & 61.82 & 63.15 & 65.33 & 66.29 & & 64.38 \\
\hline Family affluence & $3.35(0.79)$ & $3.74(0.56)$ & $3.70(0.60)$ & $3.64(0.66)$ & $* * *$ & $3.62(0.67)$ \\
\hline Neighbourhood disorg. & $7.83(3.66)$ & $7.84(3.45)$ & $7.18(3.00)$ & $7.03(2.93)$ & $* * *$ & $7.41(3.25)$ \\
\hline
\end{tabular}


Table 2. Indicators of background characteristics by type of education $(\mathrm{N}=10,525)$

\begin{tabular}{|c|c|c|c|c|c|c|c|c|c|c|c|c|}
\hline & \multicolumn{2}{|c|}{ Belgium } & \multicolumn{3}{|c|}{ the Netherlands } & & \multicolumn{2}{|c|}{ Germany } & \multicolumn{4}{|c|}{ Austria } \\
\hline & A-Track & B-Track & & A-Track & B-Track & & A-Track & B-Track & & A-Track & B-Track & \\
\hline Gender & & & $*$ & & & & & & $* * *$ & & & $* * *$ \\
\hline Boys & $50.86 \%$ & $55.75 \%$ & & $50.42 \%$ & $51.87 \%$ & & $47.68 \%$ & $54.36 \%$ & & $43.43 \%$ & $52.97 \%$ & \\
\hline Girls & $49.14 \%$ & $44.26 \%$ & & $49.58 \%$ & $48.13 \%$ & & $52.32 \%$ & $45.64 \%$ & & $56.57 \%$ & $47.03 \%$ & \\
\hline Minority group & & & $* * *$ & & & $* * *$ & & & $* * *$ & & & $* * *$ \\
\hline Majorities & $78.82 \%$ & $64.75 \%$ & & $83.47 \%$ & $63.23 \%$ & & $84.45 \%$ & $68.61 \%$ & & $83.05 \%$ & $61.82 \%$ & \\
\hline Minorities & $21.18 \%$ & $35.25 \%$ & & $16.53 \%$ & $36.77 \%$ & & $15.55 \%$ & $31.39 \%$ & & $16.96 \%$ & $38.18 \%$ & \\
\hline Parental work status & & & $* * *$ & & & $* * *$ & & & $* * *$ & & & $* * *$ \\
\hline No parents working & $6.71 \%$ & $12.93 \%$ & & $3.72 \%$ & $8.30 \%$ & & $1.67 \%$ & $6.48 \%$ & & $1.65 \%$ & $5.86 \%$ & \\
\hline One parent working & $27.52 \%$ & $35.17 \%$ & & $27.72 \%$ & $33.62 \%$ & & $27.30 \%$ & $33.36 \%$ & & $27.21 \%$ & $30.93 \%$ & \\
\hline Two parents working & $65.77 \%$ & $51.89 \%$ & & $68.56 \%$ & $58.08 \%$ & & $71.04 \%$ & $60.17 \%$ & & $71.14 \%$ & $63.22 \%$ & \\
\hline Family affluence & 3.357 & 3.344 & & 3.812 & 3.672 & $* * *$ & 3.810 & 3.612 & $* * *$ & 3.798 & 3.543 & $* * *$ \\
\hline $\begin{array}{l}\text { Neighbourhood } \\
\text { disorg. }\end{array}$ & 7.304 & 9.277 & $* * *$ & 7.217 & 8.432 & $* * *$ & 6.865 & 7.446 & $* * *$ & 6.851 & 7.146 & $* *$ \\
\hline
\end{tabular}


Table 3. Multilevel logistic regression results for lifetime prevalence rates of drinking alcohol, drunkenness, and heavy episodic drinking: unstandardized regression coefficients $(\mathrm{N}=10,525)$

\begin{tabular}{|c|c|c|c|c|c|c|c|c|c|c|c|c|}
\hline \multirow{3}{*}{ Constant } & \multicolumn{4}{|c|}{ Alcohol ltp ${ }^{a}$} & \multicolumn{4}{|c|}{ Alcohol Drunkenness Itp } & \multicolumn{4}{|c|}{ Heavy episodic drinking } \\
\hline & \multicolumn{2}{|l|}{ Model 1} & \multicolumn{2}{|c|}{ Model 2} & \multicolumn{2}{|l|}{ Model 1} & \multicolumn{2}{|c|}{ Model 2} & \multicolumn{2}{|c|}{ Model 1} & \multicolumn{2}{|l|}{ Model 2} \\
\hline & -2.585 & $* * *$ & -2.544 & $* * *$ & -4.648 & $* * *$ & -4.557 & $* * *$ & -5.118 & $* * *$ & -4.932 & $* * *$ \\
\hline \multicolumn{13}{|l|}{ Country } \\
\hline Austria & -0.029 & & -0.398 & $*$ & 0.290 & $*$ & 0.082 & & 0.010 & & -0.295 & \\
\hline Germany & 0.241 & $*$ & 0.114 & & 0.418 & $* * *$ & 0.220 & & 0.249 & $*$ & -0.137 & \\
\hline Netherlands & 0.205 & & 0.255 & & -0.078 & & -0.208 & & 0.153 & & -0.177 & \\
\hline \multicolumn{13}{|l|}{ Grade } \\
\hline Grade 8 & 0.825 & $* * *$ & 0.828 & $* * *$ & 0.897 & $* * *$ & 0.897 & $* * *$ & 0.988 & $* * *$ & 0.988 & $* * *$ \\
\hline Grade 9 & 1.464 & $* * *$ & 1.463 & $* * *$ & 1.539 & $* * *$ & 1.555 & $* * *$ & 1.653 & $* * *$ & 1.693 & $* * *$ \\
\hline Female & -0.002 & & 0.004 & & 0.024 & & 0.027 & & -0.206 & $* * *$ & -0.202 & $* * *$ \\
\hline Minority group & -0.902 & $* * *$ & -0.909 & $* * *$ & -0.557 & $* * *$ & -0.559 & $* * *$ & -0.588 & $* * *$ & -0.592 & $* * *$ \\
\hline
\end{tabular}

Parental work status

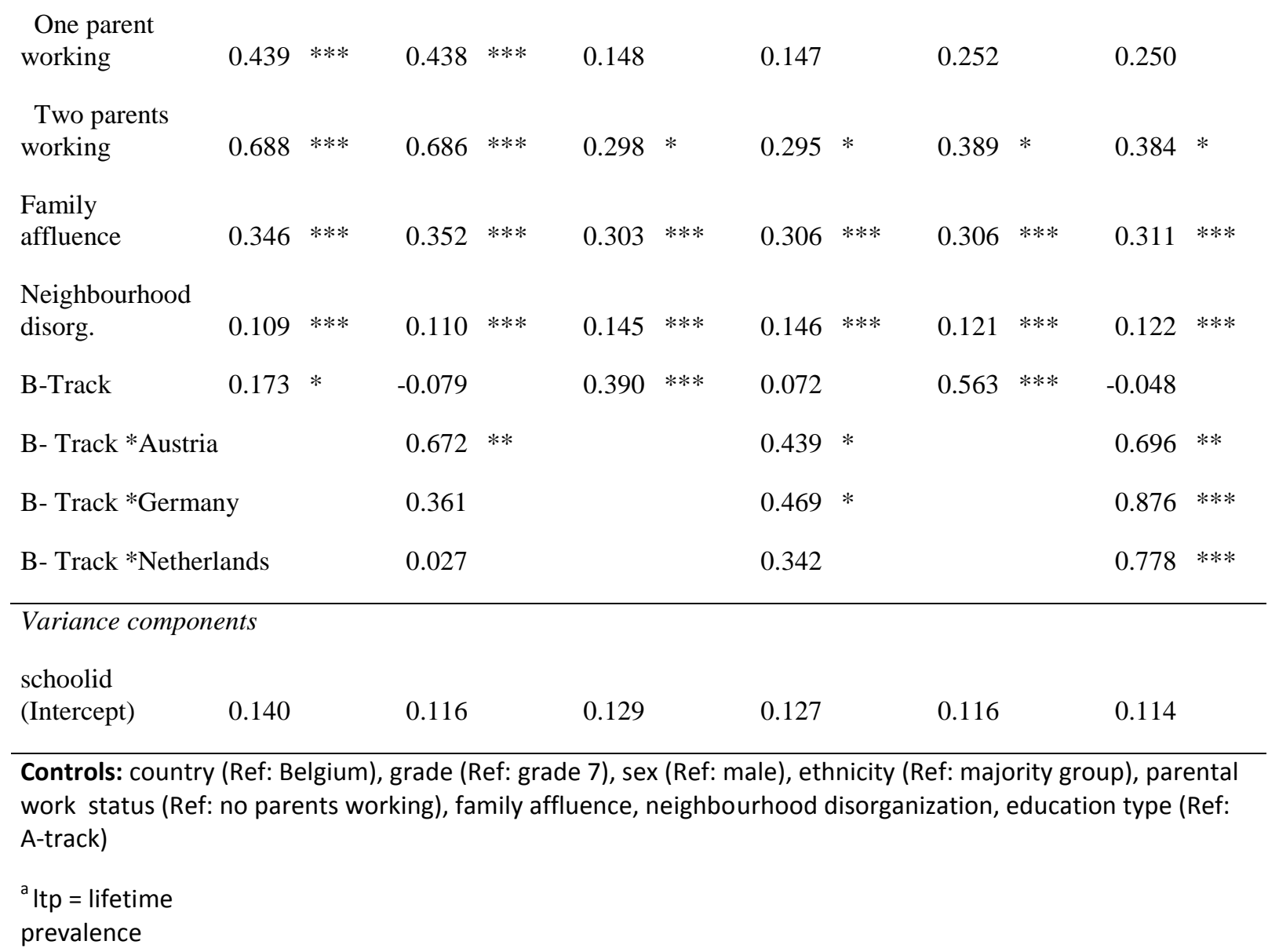


$*: p<0.05, * *: p<0.01, * * *: p<0.001$

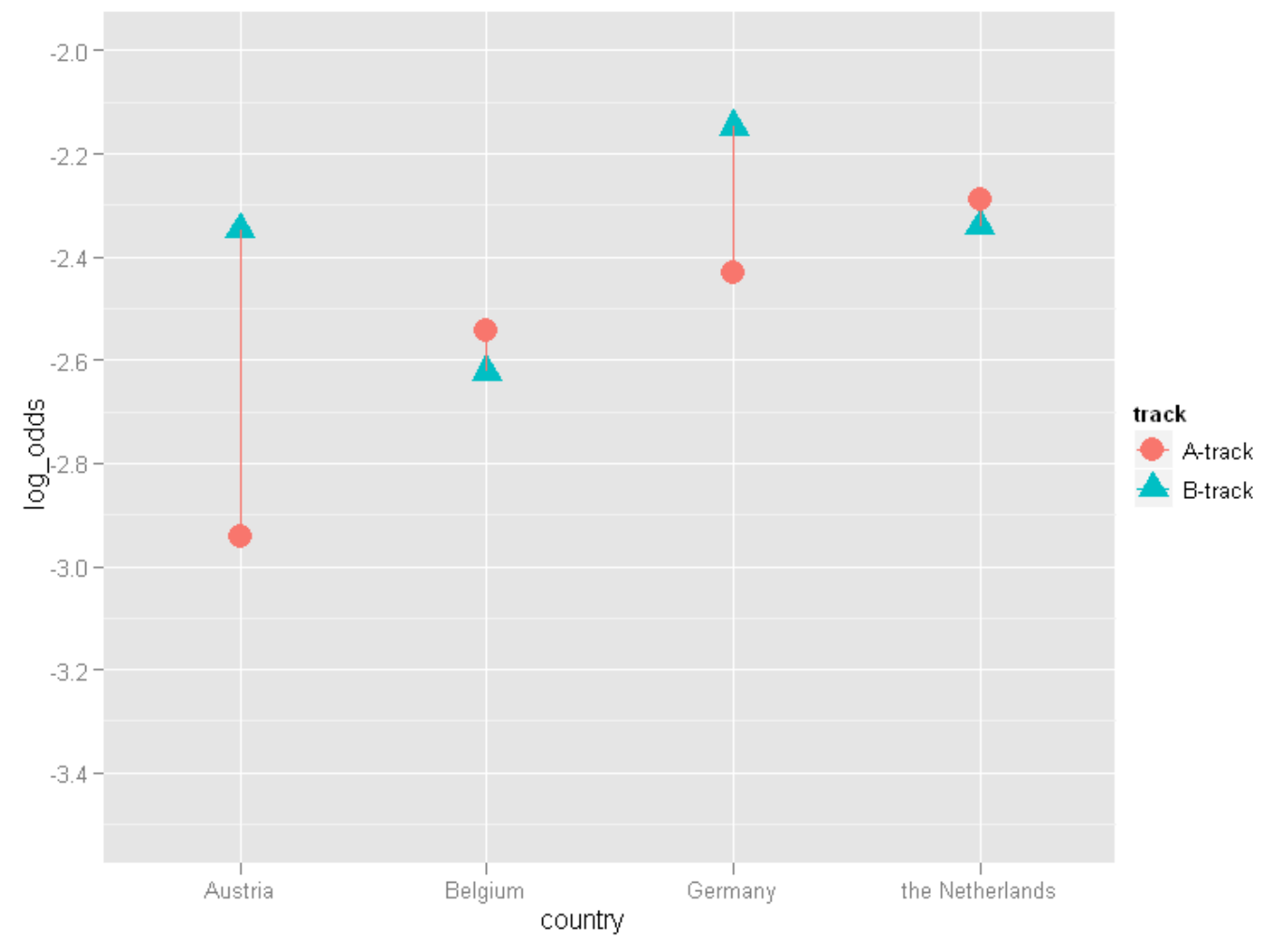

Figure 1. Effects of education type on alcohol lifetime prevalence by country 


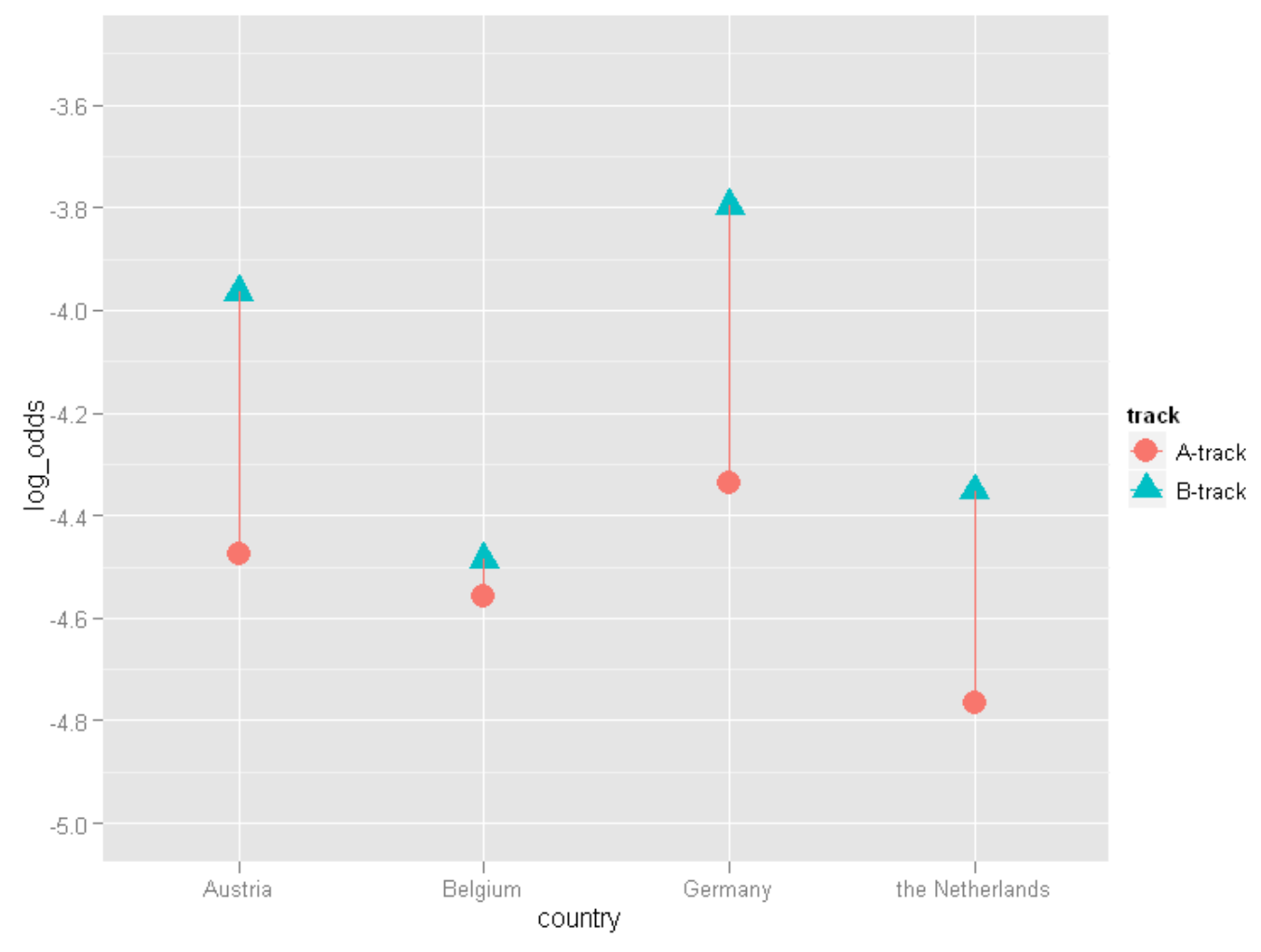

Figure 2. Effects of education type on drunkenness by country 


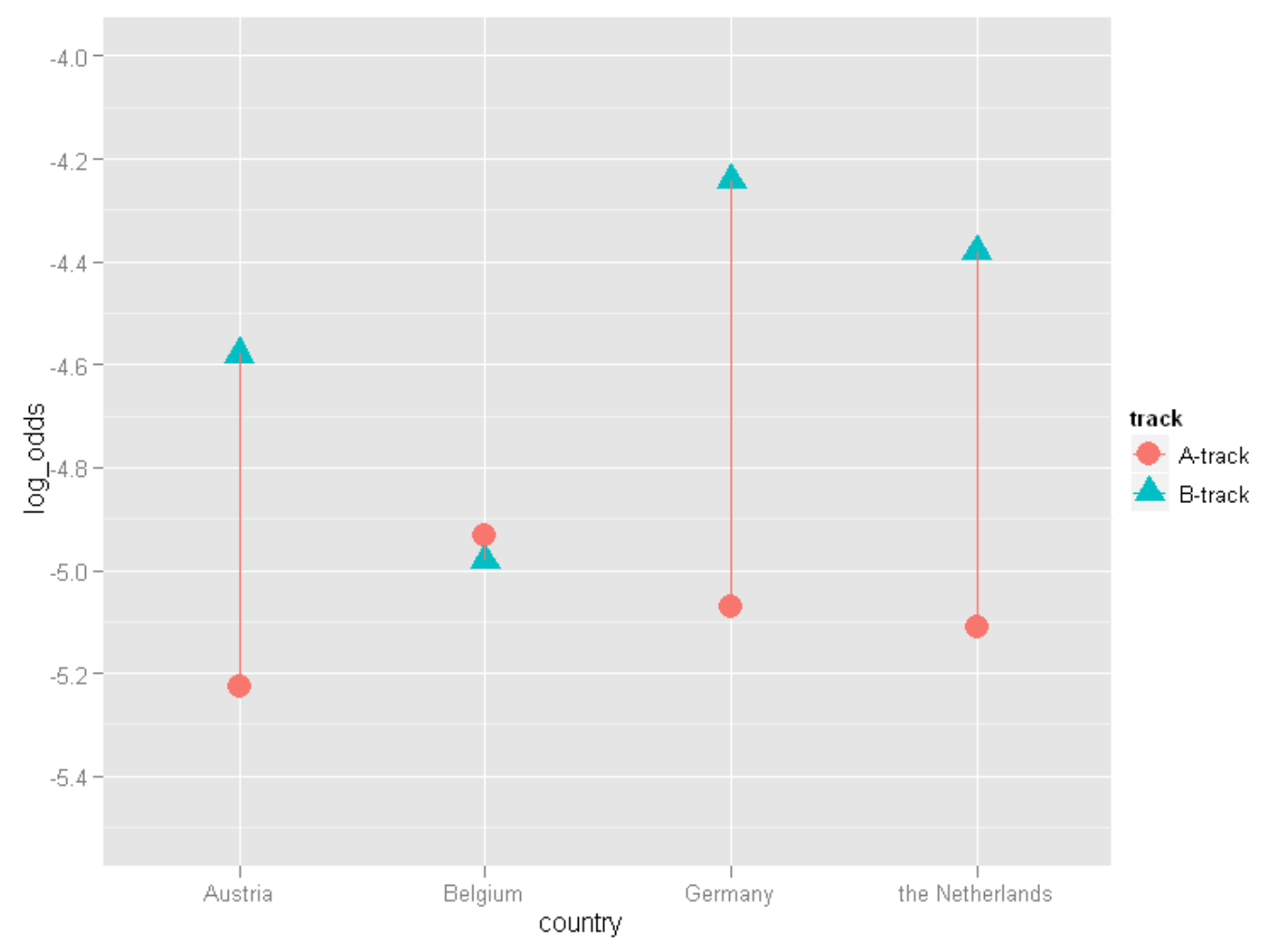

Figure 3. Effects of education type on heavy episodic drinking by country 